\title{
An Analysis on Dracula from Cultural Perspective
}

\author{
Ying Jiang $^{1} \&$ Xiao-hong Zhang ${ }^{2}$ \\ ${ }^{1}$ School of Foreign Languages, Nanjing Institute of Industry and Technology, Nanjing, China \\ ${ }^{2}$ Tongda College, Nanjing University of Post and Telecommunications, Nanjing, China \\ Correspondence: Ying Jiang, School of Foreign Languages, Nanjing Institute of Industry and Technology, \\ Nanjing, 210023, China. Tel: 86-137-7034-1070. E-mail: jiangy@niit.edu.cn
}

Received: September 11, 2012 Accepted: November 14, 2012 Online Published: November 20, 2012

doi:10.5539/ells.v2n4p100 URL: http://dx.doi.org/10.5539/ells.v2n4p100

This study was partially supported by Jiangsu Provincial Department of Education, Grant No.2012SJD750033.

\begin{abstract}
The article starts with the background introduction of Vampire as the Other in Dracula. Such traditional prejudice against the East, the black people shall be further discussed. And even the narrative method aims to define the otherness and Dracula's destiny.
\end{abstract}

Keywords: Vampire, East, black people, narrative, cultural perspective

\section{Introduction}

Bram Stoker is now widely recognized as a master of horror in literature. In his masterpiece Dracula, the hero-Count Dracula is endowed with the characteristic of evil on the basis of traditional vampires. Since its publication in 1897, it has never been out of print. And scholarly interest in this novel and its author has been aroused since the second half of the $20^{\text {th }}$ century. Especially many critics delve into the vampire symbolic of alien power. However, most of the studies are confined to the orthodox Freudian interpretation and few of them analyze the real reason for the vampire symbolic of the Other. Here the Other is designated as a form of cultural projection of concepts. The projection constructs the identities of cultural subjects through a relationship of power in which the Other is the subjugated element. Stoker, as an Irishman, feels the social prejudice against the Other acutely. However, he doesn't express his discontent over it in his works openly but in the way of the invasion of vampire so as to avoid the strict censorship of the Victorian authorities.

This article discusses how the vampire is defined as the Other and how the authorities discriminate against him all the time for their own sake based on Foucault's power theory.

\subsection{Literature Reviews}

Undoubtedly, it is a thrilling story, which attracts readers of several generations. In spite of its popularity, Dracula is initially treated by reviewers only as a sensational novel. And because classical literature was dominant at the time of its publication, it attracted little scholar's attention. "Contemporary reactions to the archetypal vampire tale at the time of its publication did not look deeper than its generic identity." (Carter, 1988) However, since the early 1970s, along with the revitalization of vampires in popular fiction, there has aroused considerable scholarly interest in vampire novels. Comments on Dracula from a variety of critical points of view are too numerous to list in detail.

Among them, one of the most famous general collections is Dracula the Vampire and the Critics edited by Margaret L. Carter in 1988, who has gathered many of the best essays together on Stoker's novels, mostly Dracula, in about three decades. In view of literary criticism, most of the studies may be categorized as historical, political, psychosexual or structural. Here I only offer a brief overview of the studies of Dracula with examples of each of these approaches.

Most of the studies of historical Dracula are relevant to legends of vampirism and the backgrounds of two prototypes of fictional Count Dracula: Vlad Tepes (a Wallachian warlord) and Elisabeth Bathory (the "Blood Countess" of Hungary). Since Bacil Kirtley published "Dracula, the Monastic Chronicles and Slavic Folklore" in 1929, many critics have delved into the legendary Dracula in history. Indeed it belongs to the most traditional 
study of Dracula.

Richard Wasson gives a new interpretation of Dracula from the political perspective. Count Dracula is symbolic of the expansion of barbaric Europeans, opposed by a Western alliance. So, in the novel Dracula's move to London marks the intersection of racial strife, political upheaval and the fall of empire.

Close reading of Dracula in terms of psychological analysis is undertaken more rigorously than others. The research can be categorized as two views: one is to show that the novel arises directly from Stoker's life experiences. Joseph Bierman is a leading critic in this respect. The other is to discuss that Stoker's portrayal of female vampires symbolizes male fear of female revolt. Based on the fact that the Count can only go where he is first visited (desired), he expresses or fulfills a need or desire for innocent victims. So, the Count arouses such feelings as sexuality and anti-maternity, which were suppressed in the Victorian England. The view prevailed in the 1970s and 1980s. Generally speaking, most of the studies are confined to the orthodox Freudian interpretation.

Here the structural analysis focuses on the narrative technique of Dracula. A few critics introduce the novel's multiple-narrator structure, such as diaries, memorandums, telegrams and newspaper cuttings, etc. But in recent years, some critics further explore Dracula's theme from the narrative point of view. David Seed compares its narration with that of Wilkie Collin's The Woman in White. Meanwhile, he stresses that in Dracula only Dracula's opponents are granted narrative voices and can record what in each case they have plausibly experienced. But in most cases, Dracula keeps silence.

From the above mentioned, though some latest studies offer new perspectives to read the text of Dracula, most critics both at home and abroad discuss the vampire symbolic of alien power only from the orthodox psychoanalytic perspective and few of them further analyze the real reason for the vampire symbolic of the Other. Here the Other, similar to that in post-colonial and feminist context, is designated as a form of cultural projection of concepts. The projection constructs the identities of cultural subjects through a relationship of power in which the Other is the subjugated element. (Edgar and Sedgwick, 1999)

\subsection{Social Context}

From the second half of the $18^{\text {th }}$ century to the whole $19^{\text {th }}$ century, the expansion of the British Empire reached a peak. The influence of the British Empire was widespread in its colonies throughout Asia, Africa, North America and Australia. It is widely acknowledged, especially by some post-colonialist critics, that the views, values and attitudes of the westerners about the colonies and the places outside the West are built on prejudice. In the eyes of the westerners, the colonial people are backward, ignorant and subordinate and therefore they need to be remolded.

Among them, Ireland is the colony of the British Empire for a long time in history. Though, throughout the $18^{\text {th }}$ century, Ireland regained a form of self-governing status through her own parliament, the parliament was abolished at the beginning of the $19^{\text {th }}$ century. From this period on Ireland becomes an integral part of a new United Kingdom of Great Britain and Ireland. In addition, the disparity between the British Empire and Ireland is broadened, especially in economy and population. The British Empire has become a modern nation, while Ireland, like East, is still a poor land. So, Stoker, as an Irishman, himself feels the social situations very acutely. In particular, he serves as a theatre manager for Sir Henry Irving for several decades in London. During the time, Stoker has an opportunity to spend a good deal of time with members of the English ruling class. His admiration for these elegant people is obviously very strong. Yet he also retains a strong sense of his Irish identity throughout his life. And Stoker has a personal and close friend, William Gladstone, "a Liberal in politics and a tacit supporter of independence for Ireland." (Belford, 1996) To some extent, under his influence, Stoker writes a pamphlet advocating Home Rule for Ireland but he is disappointed at his failure to persuade Irving to espouse this cause. As an Irishman and a dependent of Irving, it seems probable that Stoker feels like an Other among Irving's wealthy and aristocratic friends. It is likely that his external geniality conceals certain resentment against the proud English ladies and gentlemen whom he so entertains. There is no Irish character in Dracula but there is such the Other as the vampire, especially the erotic, demonic and vengeful Count Dracula.

\section{East-An Other Zone}

In the $19^{\text {th }}$ century, the inventions of the steam engine, telegraph, telephone, electric light and new discoveries in medicine changed the way people lived, particularly in Western Europe. But the changes are slow to reach into East (including Eastern Europe and Asia, etc.). So, Eastern Europe is often characterized as backward and inferior to Western one in culture, language and customs. Especially the concepts of Balkans bring images of civil wars and hatred. The people from these regions are barbarian, primitive, poor and irredeemable in contrast 
with those from civilized and developed regions in the West. It is no wonder that the civilized nations distance themselves from the barbarian.

At that time, The British Empire was a most powerful country. Consequently, there has always been full of such consciousness that West is bringing civilization to primitive or barbaric people. East is desolate, while West is highly industrialized. According to the westerners, East is the symbol of barbarism-Other, leave alone the person from East, who is inevitably defined as inferior Other. So, they are entitled to remold the Other and even rebuild the Other freely, which serves well the so-called civilization.

As a cultural and ethnic concept, the term-Eastern Europe was defines as opposed to Western Europe in the $19^{\text {th }}$ century. Dracula also focuses on the conflicts between Western and Eastern Europe. "No doubt that numerous psychological and sociological explanations for the novel's popularity might be offered; among these possibilities is a political theme which would appeal to audiences throughout the series of crises presented by the two world wars and the cold war. Count Dracula ... in the novel represents those forces in Eastern Europe which seek to overthrow, through violence and subversion, and more progressive democratic civilization of the West." (Wasson, 1988) To a large extent, Dracula is interpreted as the threat of the barbarian attempting to overtake the civilized world.

In Dracula, Jonathan Harker, whose journal begins the story, takes trains-a symbol of progress in industrial society - to Dracula Castle. However, the deeper he goes to the East, "the more unpunctual are the trains. What ought they to be in China?" (Stoker, 1998) As for Harker who has been accustomed to the Western life, the East seems to fail to keep up his pace. Harker observes Transylvanian, at least at first, as he has read about in the British Museum: "little towns or castles...such as we see in old missals." (Stoker) Museum often refers to a depository for collecting and displaying objects having historical value. Obviously, in Harker's eyes, the East seems undeveloped as before. The place where the story happens, near the border of three Balkan territories in the center of Romania, is also suggestive enough. Jonathan Harker describes it as a distinctly eastern portion of Europe where the laws and customs of the West do not apply. He writes in his diary: "certainly an imaginative whirlpool of races... where hardly a foot of soil has not been enriched by the blood of men, patriots, invaders." (Stoker) While the Western Europe frees herself to develop economy and education, etc. Instead, the Eastern one is still exhausted by wars, let alone civilization. For example, when Harker is aware that he has become a prisoner and even lost the elementary right as a prisoner, he is at the end of his wits. "It makes me rage to think that this can go on, and whilst I am shut up here, a veritable prisoner, but without that protection of the law which is even a criminal's right and consolation." (Stoker)

The political theme becomes more complicated in the novel. From one aspect, in the old days the Count had to exist on the primitive frontier of Western culture, whereas now his best chance for survival is in England, the most progressive, rational and democratic nation in Europe. From the other aspect, it is obvious that modern victory can be better won by subversion than by invasion. Because technological progress has cut humanity off from the old superstitious and dark knowledge, civilized man has no defense against them.

So, Dracula has been understood to respond to the fears of late Victorians. "Most notably Dracula has received considerable critical attention on the novel's reliance on a model of degeneracy that articulates contemporary anxieties relating to criminality and race." (Smith, 2003) Due to Darwinian thought, degeneration threatens both the British race and the British Empire. Indeed, racial Other is another important factor for Dracula's destiny.

\section{Dracula-A Racial Other}

This part discusses the identity of Dracula. The question of one's identity is a very simple and a very complex issue. Identity refers to "the qualities and attitudes you have that make you feel you have your own character and are different from other people" in Longman Dictionary of Contemporary English (Third Edition). The affirmation of one's identity is an inner and unconscious demand. An individual tries to confirm his/her identity in order to obtain, maintain and protect a kind of psychological security, which is vital to a stable and healthy psyche. However, such an affirmation is not easy to achieve. From the definition of identity, one will find that it is constructed in contrast with "other people". So, one has to draw a line between "his/her own kind" and "the other" as identity is based on contrast.

If Dracula is the embodiment of the Other, what is he other than? To answer this question, we must look briefly at the "good" characters in Dracula. Some of these characters (Quincey Morris, Arthur Godalming, Lucy Westenra and Mina Harker) are independently wealthy; others (Jonathan Harker, Dr. Seward and Prof. Van Helsing) are engaged in such eminently respectable professions as law or medicine. However, they seem less to earn a living than to do good for humanity. Anyhow they are all members of the ruling class in England. Among them, Godalming represents bourgeois aristocrat, i.e., English tradition while Harker and Seward represent the 
group that keep English society functioning: as a lawyer, Harker represents the state, the juridical and political system; Seward is a psychiatrist, dedicated to exploring the causes of unreason and eliminating them. The key decisions in the Victorian society are made by people like Godalming, Harker and Seward; they justify their power and privilege from such women as Lucy Westenra and Mina Harker. They are immune from such human feelings as lust, envy, anger and fear until Count Dracula appears. The other two "good" characters are not English but they are also dedicated to protecting the purity of England, too: one is Quincey Morris, a rich Texan, who proposes Lucy early in the novel. Though he is refused by her, he still dedicates himself to serving for her. His devotion to the cause of women's purity seems to make him at least an honorary Englishman. The other foreigner is the Dutch doctor Van Helsing, who is undoubtedly the most memorable of the "good" male characters. He also shows his virtue by wholeheartedly dedicating himself to protecting the purity of English women. So, by comparison with the above mentioned "good" characters, Dracula's identity as the Other can be defined from the following three aspects.

\subsection{English Intonation}

Firstly, Dracula's identity as a racial outsider is suggested by some of his conversation with no good mastery of the English language. Even Dracula himself has the same feeling. He intends to learn English intonation with Harker early in the novel for he aims at speaking English in London like a native. Though Dracula is a "boyar" and a "master" (Stoker) in Transylvania, he can't enjoy the respected atmosphere at will in London-the most developed and flourishing city all over the world. In order to avoid becoming a stranger in a strange land, he would correct the smallest error in his speaking.

\subsection{Peculiar Sexual Tastes}

Secondly, his peculiar sexual tastes are the key factor as a racial outsider because no Englishman would do something like that as above-mentioned. Dracula seduces Victorian woman into giving up her conservative thought in sex. Unconsciously, the woman breaks away from the male domination and pursues her own happiness in sex. Foucault describes a progressive logic by which "perversion-hereditary-degenerescence" (Foucault 1980) becomes the basis of nineteenth-century scientific claims about the danger of undisciplined sexuality. Sexual perversions lead, potentially, to the decline of future generations. Furthermore, Foucault claims theorizing degeneration as the result of hereditary perversion takes the "coherent form of a state-directed racism" (Foucault 1980). It is no exaggeration to say that the dread of sexual perversion resulted in the hate for other race like Dracula in the Victorian age.

More often than not, the biological appearance of a person is a remarkable feature when it is thrown against a sharp different background. So the sexual ambience that surrounds him is also worth discussing here. As Cleaver states in Soul on Ice, dark men are sexually more vigorous than fair men, which is deeply ingrained in Western civilization. And Stoker's portrait of Dracula is partially shaped by it. Dracula's skin is, of course, pale. However, black and darkness seem to have natural attraction for him: he likes wearing his black clothes and cape at night; and he always does all he can to enter his/her bedroom at midnight through windows once he finds a potential victim. All these images combine to make him an archetype of the dreaded black rapist.

Dracula's hand has "hairs in the centre of the palm" (Stoker) with long and pointed nails, which is similar to that of the primitive. His appearance is marked as the Other, which makes Harker throw doubt on him to some extent.

\subsection{Strange Smell}

Thirdly, that Dracula symbolizes the racial outsider is also suggested by his smell. This subject is repeatedly referred to by the narrators of the novel, especially Harker:

As the Count leaned over me and his hands touched me, I could not repress a shudder. It may have been that his breath was rank, but a horrible feeling of nausea came over me, which, do what I would, I could not conceal.... There was an earthy smell, as of some dry miasma, which came through the fouler air. But as the odour itself, how shall I describe it? It was not alone that it was composed of all the ills of mortality and with the pungent, acrid smell of blood, but it seemed as though corruption had become itself corrupt. Faugh! It sickens me to think of it. Every breath exhaled by that monster seemed to have clung to the place and intensified its loathsomeness. (Stoker 18)

The notion that Dracula's smell is different from other people is a recurrent theme. Furthermore, the supposed smell of the Other ("we," of course, don't smell) is clearly associated with their presumed hyper-sexuality. "As Freud argued, there seems to be an inescapable connection between sex and smell. The fear that the racial outsider will creep out of the stinking sewer to rape our women (and then, probably, slit our throats too) has been endemic in our century; and in the figure of Count Dracula we find a nightmarish embodiment of these fears." 
(Hatlen 129) When Harker and his band of friends break into Carfax — one of Dracula's houses in London, they are all nauseated by a smell "composed of all the ills of mortality and with the pungent, acrid smell of blood" (Stoker). They hardly bear it. "Under ordinary circumstances such a stench would have brought out enterprise to an end." (Stoker) However difficult their fight is, they have lofty belief of saving the humanity, at least in their own conceit.

The various signs of Dracula as the Other-his accent, "dark" sexuality and foul smell-make him a representative of all dark foreigners. It seems Stoker, to some extent, identifies himself with Dracula, who is symbolized as a dark avenger to punish the English for their insults against himself and his people.

So, the people from uncivilized regions should not be treated as inferior by the civilized for their own sake, which will result in the aggravation of their contradictions just as Dracula returns as an avenger.

\section{The Other in Narrative}

Bram Stoker writes the novel in the diary form. The whole story is composed of not only diaries and letters (which are quite traditional in novels), but also memorandums, telegrams, railway timetables, newspaper cuttings, monumental inscriptions, notebooks, phonographically recorded case-notes of psychiatry and a ship's log translated from the Russian. It is very beneficial to the plot of Dracula. In a diary, extensive descriptions and large emotional feelings can be expressed and felt by the reader; and during the usage of letters, two people conversing can be written out in dialogue form; when the newspaper cuttings are used, the reader will have the freedom to think and draw his/her own conclusion from the article. As Maud Ellmann summarizes, "One of the reasons for using such a method, particularly in supernatural tales of terror, is to make an incredible story more credible by providing plenty of good witnesses to vouch for it. In the case of Dracula, it also serves to emphasize the importance of collaboration, which (as Van Helsing points out) is the great weapon that the vampire-hunters can deploy against the solitary Count." (Ellmann 1998) Since the diary form is so convincing, Dracula places an insignificant role in narrative, to be exact, hardly has any voice in the novel.

When the "good" characters plan to unite to deal with Dracula, they, especially Mina, spare no effort to gather every scrap of documentation in order of time of occurrence. Van Helsing and his team of vampire-hunters attempt to build a fortification of knowledge against the threat of the Other based on the materials.

It is worth noting here that despite the variety of documentary sources, the narrative episodes are recorded, transcribed, edited and compiled throughout the novel by four respectable middle or upper class Englishmen: Mina Murray, Lucy Westenra, Jonathan Harker and Dr John Seward. The narrative controlled by these characters suggests that the textual body, like the bodies of the women of England, must be protected from any corrupting or foreign influence. The foreigners, especially Dracula, are for the most part elbowed out of the narrating position.

In fact, the activities of reading and writing are crucial in this novel to establish a kind of middle-class hegemony. It can be said that social standards seem to be a subjective production, which is revealed as the completely controlled mass-production of a group of doctors, psychiatrists and lawyers. Writing, or at least who writes, must be controlled since it represents the deployment of knowledge. Similarly, reading must be authorized and censored. According to Foucault's view, there is a link between knowledge and power. To be exact, knowledge is to gain power. When Mina falls under the vampire's influence and Dracula begins to read her mind, she is barred from reading the English group's plans. Similarly, the English men eliminate Dracula's contaminated opinions from the narrative; he almost has no voice but is read and written by all the other characters in the novel, especially after Jonathan Harker's sojourn at Castle Dracula in chapters 1-4. Therefore, his appearances are few, momentary, often ambiguous and mostly silent. He appears as a wolf or a bat; he appears in second-hand accounts, that is, reports from the other chief narrators. In London he has precisely two speaking appearances in the accounts of the primary narrators: Mina's dictation of his attack upon her and his confrontation with the five heroes in London. So, the narrative enables the English middle-class characters to consolidate their victories over the Other in all its forms.

Besides, in Dracula, a great thing that is controlled wonderfully in the diary form is time. As a matter of fact, Dracula's failure is partly attributed to his lack of time concept. When Van Helsing arrives on the scene, he immediately warns Seward of the fallibility of memory. He tells Seward: "Remember, my friend, that knowledge is stronger than memory, and we should not trust the weaker... Take then good note of it. Nothing is too small. I counsel you, put down in record even your doubts and surmises." (Stoker) Why does Van Helsing hold the opinion that knowledge is stronger than memory? Knowledge is tied to time and knowledge evolves from the comparison of written sources and lived experiences. Consequently, the documentary that establishes knowledge erases memory. Seward is urged to record all his doubts and surmises so that they can be compared with the 
ongoing experiences that shed light on the written record and correct it. Indeed, Van Helsing regrets how long it takes him to believe in the fact of the vampire with the result that Lucy loses her life. In contrast to Van Helsing's obsession with controlling time, the Count has no control of time, to be exact; his thought is a long way behind that of modern man. For example, because his conspiracy is brought to light by the band of men, he finds himself no place to hide in London. So, he has no choice but to escape and return to his den-Transylvania via Varna. But he chooses ship as his vehicle. As Van Helsing analyzes, "it will take her [the ship] at the quickest speed she has ever made at least three weeks to reach Varna; but we can travel overland to the same place in three days." (Stoker) It is obvious that he lags behind the industrial society. Whatever power he has, he can't compete against the "good" character.

In the end, the vampire, born in a foreign land, is destroyed without any complaint. He is doomed to be excluded by the society as Foucault says:

So formerly, unreason was set outside of judgment, to be delivered, arbitrarily, to the powers of reason. Now it is judged, and not only upon entering the asylum, in order to be recognized, classified, and made innocent forever it is caught, on the contrary, in a perpetual judgment, which never ceases to pursue it and to apply sanctions, to proclaim its transgressions, to require honorable amends, to exclude, finally, those whose transgressions risk compromising the social order. (Foucault 1988)

\section{Conclusion}

In the $19^{\text {th }}$ century, England was the most powerful country in the world. In the English eyes, Eastern Europeans, symbolized as barbarian and uncivilized, seek to overthrow their civilization and progress. Especially Dracula's accent, "dark" sexuality and foul smell make him a representative of all dark foreigners in the Victorian society. In addition, Dracula is an epistolary novel. However, because the activities of reading and writing are crucial in this novel to establish a kind of middle-class hegemony, Dracula, as the Other, is inevitably elbowed out of the narrators.

It is Other himself, not a particular social group that Dracula represents. For the "good" characters in the Victorian age, the modes of otherness were infinite. However, they intend to construct a harmonious society: no Other power, no Other culture and no Other voice by all means. On the contrary, under their suppression, the Other comes to London with much bitter personal hatred, which is not helpful to attain the harmony of the whole society.

\section{References}

Belford, Barbara. (1996). Bram Stoker: A Biography of the Author of Dracula. New York: Alfred A. Knopf, Inc.

Carter, Margaret L. (Ed). (1988). Dracula the Vampire and the Critics. London: UMI Research Press.

Edgar, Andrew, \& Sedgwick, Peter. (1999). Key Concepts in Cultural Theory. London; New York: Routledge.

Ellmann, Maud. (1998). Introduction. In Bram Stoker. Dracula. England: Oxford University Press.

Foucault, Michel. (1980). The History of Sexuality (Robert Hurley, Trans.). New York: Vintage Books. http://dx.doi.org/10.1002/9780470755501.ch17

Foucault, Michel. (1988). Madness and Civilization (Richard Howard, Trans.). New York: Random House. http://dx.doi.org/10.4324/9780203278796

Hatlen, Burton. (1988). The Return of the Repressed/Oppressed in Bram Stoker's Dracula. In Margaret L. Carter (ed.), Dracula the Vampire and the Critics (pp. 117-135). London: UMI Research Press.

Smith, Andrew. (2003). Demonising the Americans: Bram Stoker's Postcolonial Gothic. Gothic Studies, 5(2), 20.

Stoker, Bram. (1998). Dracula. Oxford: Oxford University Press. http://dx.doi.org/10.5117/9781904633143

Wasson, Richard. (1988). The Politics of Dracula. In Margaret L. Carter (ed.), Dracula the Vampire and the Critics (pp. 19-34). London: UMI Research Press. 